\title{
A eugenia na teoria da justiça: a tensão entre a liberdade individual $e$ o aborto de fetos com microcefalia*
}

\author{
André Luiz Silveira de Lima Júnior** \\ Bianka Adamatti**
}

Recibido: 22 de junho de 2016 • Aprobado: 4 de novembro de 2017

https://doi.org/10.22395/ojum.v17n34a12

\begin{abstract}
RESUMO
Uma das grandes preocupações recentes das mulheres gestantes foi a expectativa de saber se seu filho fora atingido pelo surto de microcefalia no Brasil e em boa parte do continente latino-americano desde o final de 2015. Diferentemente de outras más formações, como a anencefalia, ela não impede o nascimento com vida ou reduz a sua expectativa, mas pode causar necessidades especiais, as quais geram questionamentos sobre a interrupção da gravidez, caso em que pode ser considerada como uma forma de eugenia. Diante disso, no decorrer deste trabalho, é verificado se há eugenia e a qual o caso pertence; posteriormente, ocorre uma análise, sob a perspectiva da justiça política, de autores filiados ao neokantismo, em especial Jürgen Habermas e John Rawls. Para responder às indagações, utilizou-se o método dedutivo, através da pesquisa bibliográfica. Chegou-se à conclusão de que o fundamento da maximização das liberdades pode ser um impeditivo moral na conduta abortiva de fetos microcéfalos, desde que o fim eugênico seja mera e comprovadamente utilitarista.
\end{abstract}

Palavras-chave: Microcefalia; eugenia; aborto; justiça política; bioética.

\footnotetext{
Este artigo é fruto do trabalho em conjunto dos autores no Núcleo de Direitos Humanos (NDH), da Universidade do Vale do Rio dos Sinos (Unisinos), em que ambos foram pesquisadores associados durante o período de pós-graduação no nível de mestrado.

** Advogado formado pela Universidade Federal de Goiás, Goiânia, Brasil. Mestre em Direito Público pela Unisinos, São Leopoldo, Brasil. Doutorando em Direito na Universidade Federal de Santa Catarina, Florianópolis, Brasil. E-mail: andre.lima.junior@posgrad.ufsc.br

*. Bacharela em Direito pela Unisinos, São Leopoldo, Brasil. Mestra em Direito Público pela Unisinos, São Leopoldo, Brasil.E-mail: bianka.adamatti@hotmail.com.
} 


\title{
Eugenics in the theory of justice: the tension between individual freedom and the abortion of foetuses with microcephaly
}

\begin{abstract}
One of the greatest recent concerns of pregnant women has been the expectation of knowing if their child has been affected by the microcephaly outbreak in Brazil and much of Latin America since late 2015. Unlike other malformations, such as anencephaly, microcephaly does not prevent live birth or reduce life expectancy, but it can cause physical and mental disabilities, which raise concerns about termination of pregnancy, in which case it can be considered a form of eugenics. In view of the above, the text verifies whether there is eugenics and to which case it belongs; subsequently, there is an analysis, from the perspective of political justice, of authors subscribed to neokantism, especially Jürgen Habermas and John Rawls. In order to answer the inquiries, the deductive method was used, by means of bibliographic research. It was concluded that the foundation of maximization of freedoms can be a moral impediment in the abortive conduct of microcephalic fetuses, as long as the eugenic end is merely and verifiably utilitarian.
\end{abstract}

Keywords: Microcephaly; eugenics; abortion; political justice; bioethics.

\section{La eugenesia en la teoría de la justicia: la tensión entre la libertad individual y el aborto de fetos con microcefalia}

\section{RESUMEN}

Una de las grandes preocupaciones recientes de las mujeres gestantes ha sido la expectativa de saber si su hijo se ha afectado por el brote de microcefalia en Brasil y gran parte de Latino América desde finales del 2015. A diferencia de otras malas formaciones, como la anencefalia, la microcefalia no impide el nacimiento con vida o reduce su expectativa, pero puede causar discapacidades físicas y mentales, las que generan inquietudes acerca de la interrupción del embarazo, caso en que puede ser considerada como una forma de eugenesia. Ante lo anterior, en el texto, se verifica si hay eugenesia y a cuál el caso pertenece; posteriormente, ocurre un análisis, desde la perspectiva de la justicia política, de autores suscritos al neokantismo, en especial Jürgen Habermas y John Rawls. Para contestar las indagaciones, se utilizó el método deductivo, por medio de la investigación bibliográfica. Se concluyó que el fundamento de maximización de las libertades puede ser una impeditiva moral en la conducta abortiva de fetos microcefálicos, siempre y cuando el fin eugenésico sea mera y comprobadamente utilitarista.

Palabras clave: Microcefalia; eugenesia; aborto; justicia política; bioética. 


\section{INTRODUCÃO}

A partir de 2015, a preocupação sobre o surto de bebês com microcefalia tomou grandes proporções devido à ampla cobertura da mídia e ao alastramento de casos por todo o Brasil e alguns locais da América Latina. Inicialmente com o surto concentrado na região nordeste do país, a origem da doença ainda permanece dúbia, embora haja uma indicação de que o zika vírus seja o causador dessa má formação fetal.

O foco do estudo em questão, porém, não é atribuir a responsabilidade da microcefalia a nenhuma causa específica, mas sim discutir a possibilidade de a mulher informada de tal quadro abortar.

De antemão, faz-se necessário definir o que se entende por microcefalias. Como aponta o Ministério da Saúde do Brasil (2015), elas são:

definidas como alterações de estrutura ou função do corpo que estão presentes ao nascimento e são de origem pré-natal (1). Segundo a Organização Mundial da Saúde (OMS) e literatura científica internacional, a microcefalia é uma anomalia em que o Perímetro Cefálico (PC) é menor que dois (2) ou mais desvios-padrão (DP) do que a referência para o sexo, a idade ou tempo de gestação (1 -7). A medida do PC é um dado clínico fundamental no atendimento pediátrico, pois pode constituir-se na base do diagnóstico de um grande número de doenças neurológicas e para isso os médicos e outros profissionais de saúde devem estar familiarizados com as doenças mais frequentes que produzem a microcefalia e devem conhecer os padrões de normalidade para o crescimento do crânio (3). (p. 12)

Especificamente no Brasil, criou-se um ambiente propício para um embate entre setores conservadores e progressistas da sociedade - de forma similar ao aborto de fetos anencefálicos. Isso porque a opinião pública passou a refletir sobre uma eventual ação de Arguição de Descumprimento de Preceito Fundamental (ADPF) no Supremo Tribunal Federal (STF) para se permitir o aborto de indivíduos com microcefalia comprovada, tendo em vista a negligência do Estado no controle do surto da doença e o público atingido, em sua maioria, ser composto de mulheres de baixa renda, em situação de vulnerabilidade.

Quando um embrião é acometido de microcefalia, a criança nasce com vida, porém "pode ser acompanhada de epilepsia, paralisia cerebral, retardo no desenvolvimento cognitivo, motor e fala, além de problemas de visão e audição" (Ministério da Saúde do Brasil, 2015, p. 19), diferentemente da anencefalia, cuja vida após o nascimento torna-se inviável, com a sobrevida curta. Diante disso, o presente trabalho discute se o método de interrupção de gravidez em caso de fetos microcéfalos pode ser considerado como eugenia negativa.

Para o desenlace da questão, a pesquisa está distribuída em duas partes: a primeira tem como objetivo trabalhar com o 
fenômeno da eugenia e suas faces, a fim de classificar a interrupção da gestação dos fetos microcéfalos em eugenia positiva ou negativa; na segunda, por sua vez, após a adequação do caso aos tipos apresentados, é analisada a questão da justiça, a partir de uma perspectiva política de matriz neokantiana, sobretudo com a obra Uma Teoria da Justiça, escrita por John Rawls (2008), apresentando, nessa parte, os aspectos gerais de seu pensamento, para verificar se, sob a ótica do autor, o aborto de fetos microcéfalos seria permissível no referido contexto.

No intuito de melhor responder à problemática da pesquisa, o método utilizado foi o dedutivo, realizado a partir de material bibliográfico. Como possível resposta, encontrou-se que, ainda que a liberdade seja fundamental para a consecução da justiça nos ditames rawlsianos, mediante o estabelecimento de um princípio a ser aceito por todos quando ignorantes de sua posição na sociedade, a mera instrumentalização de seu dispositivo para fins utilitários não merece prosperar; afinal, estaria tornando meio aquilo que deveria ser, na verdade, fim em si mesmo.

\section{A INTERRUPCÃO DA GESTACÃO DE FETOS COM MICROCEFALIA: EUGENIA POSITIVA OU NEGATIVA?}

Desde o seu início genealógico, a eugenia buscou, mediante a crença nos estudos técnico-científicos, a "melhoria" da qualidade de vida da sociedade. Independentemente de assumir um discurso duvidoso sobre a real intenção daqueles que o assumem, esse fenômeno ainda é considerado polêmico, sobretudo pela penumbra deixada pelo nazismo ao utilizar certa "racionalização" em seus experimentos em pessoas.

Já no século XXI, é bem verdade, o avanço da ciência e a difusão do conhecimento da manipulação genética levaram a novos desafios e paradigmas, os quais serão expostos no decorrer deste capítulo, a fim de indicar o atual estado da arte em torno da eugenia.

\section{1.l A eugenia de Francis Galton: do surgimento até 0 século atual}

No ano de 1908, nascia a primeira organização para estudos sobre a eugenia. Fundada em Londres, seus estudiosos a defendiam como solução da propagação de doenças hereditárias e de seres humanos incapazes, portadores de deficiências física e/ou mental (Domingues, 1942). Francis Galton, considerado o grande mentor dessa ideia, a conceitua da seguinte forma: "La eugenesia es la ciencia que trata de todas las influencias que mejoran las cualidades innatas de una raza; también trata de aquellas que la pueden desarrollar hasta alcanzar la máxima superioridad" (Galton, 1988, p. 165).

Segundo os eugenistas, o objetivo dessa ciência é a busca do conhecimento para a melhoria física, mental e/ou social da constituição biológica das gerações futuras. Os pesquisadores se consideram como "os verdadeiros seguidores das ideias de Darwin, uma vez que interpretam o problema social da reprodução a partir 
do problema biológico da competição de recursos" (Domingues, 1942, p. 29).

Há a afirmação da existência de uma má compreensão do instituto da eugenia, cujo objetivo principal seria, na verdade, aumentar o número daqueles com grande capacidade intelectual e física, o que diminuiria os "inferiores", denominados inaptos (Domingues, 1942). Domingues (1942), eugenista brasileiro, afirma que:

\begin{abstract}
O homem estudioso verificou, por observação e por meio de experiências, que as qualidades físicas, intelectuais e morais da espécie, têm um fundo hereditário indiscutível. Deste modo, quando se unirem duas pessoas sãs de corpo e de espírito, sua descendência terá as maiores probabilidades possíveis de ser constituída por indivíduos também de corpo e alma sadios. Pelo contrário, de um casal de tarados, ou fisicamente defeituosos, só se poderá esperar uma descendência nas mesmas condições. Daí a eugenia ensinar que convém promover aquelas uniões e evitar estas últimas. (p. 31)
\end{abstract}

Segundo Mota (2013), ocorre uma diferenciação entre a eugenia positiva e a negativa: a primeira defende a perspectiva de promover o progresso físico e moral no futuro, através da aplicação do melhoramento genético na população humana. A negativa, por sua vez, prega que, se a inferioridade é uma característica hereditária (assim como as melhores qualidades humanas) e não decorrente das condições ambientais, sociais e educacionais (Del Cont, 2008), a única forma de impedir a degeneração da espécie humana seria por meio da utilização de métodos como esterilização, abortos seletivos, segregação e adoção de leis de imigrações restritivas.

Habermas, pensador alemão oriundo da corrente neokantiana e filiado à Teoria Crítica, defende a regulação das intervenções terapêuticas, isto é, aquelas voltadas a evitar doenças genéticas graves. Contudo, opõe-se à eugenia que propõe a melhoria do ser humano; a justificativa do filósofo alemão, conforme Feldhaus (2005), refere-se ao consentimento. A justificação dessa distinção é o critério normativo do consentimento presumido. Habermas defende que intervenções que visam eliminar ou evitar doenças com base genética poderiam ser aceitas ou ao menos ser presumidas que seriam acolhidas ou consentidas pela pessoa geneticamente manipulada, ao passo que as intervenções que adentram no terreno do aperfeiçoamento não poderiam contar com esse tipo de consentimento, portanto deveriam ser proibidas.

Na perspectiva habermasiana, as intervenções genéticas parecem estar sem limites, principalmente sob o aspecto da dignidade humana, pois não há o devido esclarecimento sobre as consequências desses procedimentos. Além disso, acredita-se que, por muitos procedimentos acarretarem efeitos irreversíveis, afetarão a liberdade, a autocompreensão, já que se trata de uma mudança estrutural no ser humano.

Cowan (1972) afirma que Galton, por sua vez, ao dar enfoque ao critério ne- 
gativo da eugenia, acreditava que, caso não houvesse um controle da qualidade reprodutiva dos indivíduos na sociedade, em pouco tempo, o resultado seria o desenfreado nascimento de pessoas consideradas degeneradas, como vadios, alcoólatras, prostitutas, dementes e portadores de doenças generalizadas. Com isso, chega-se à conclusão de que a eugenia, para o seu mentor, pode acarretar na sociedade uma carga tanto benéfica, ao contribuir com o controle de doenças genéticas, quanto maléfica, ao criar um parâmetro de seres humanos que poderão ser segregados e eliminados por não se encaixarem nos padrões sociais pré-estabelecidos, como ocorreu na Alemanha Nazista. ${ }^{1}$

Buchanan, Brock, Daniels e Wikler (2002) afirmam que, por meio da utilização da atividade científica, seria possível reduzir a incidência de enfermidades genéticas graves, o que melhoraria a qualidade de vida e longevidade das pessoas, como também aperfeiçoaria a memória e as capacidades intelectuais. Algumas clínicas especializadas — como a Fertility Institutes, em Los Angeles — oferecem a Pre-implantation Genetic Diagnosis, procedimento em que é possível selecionar o padrão estético dos futuros filhos, através da mesma técnica utilizada para evitar doenças congênitas graves em recém-nascidos.

Habermas (2004) diz que a eugenia liberal é gênero que comporta duas espécies: (1) eugenia positiva (aperfeiçoamento) e (2) eugenia negativa (intervenções para evitar doenças genéticas graves).
São notórias as pesquisas na área nos Estados Unidos e em alguns países europeus, como é o caso da Itália, em que médicos anunciaram a cura de uma doença que tira a capacidade das crianças de andar e falar, por meio de uma técnica pioneira de terapia genética para corrigir erros no DNA. O procedimento retira células-tronco do paciente, e o vírus é usado para "infectar" as células a partir de fragmentos de DNA, os quais contêm as instruções corretas. Estas, por sua vez, são colocadas novamente no paciente, para corrigir as mutações prejudiciais.

O Brasil, como mostra o caso de Maria Clara, a primeira brasileira nascida através da seleção genética, também avança nos estudos desse campo. O seu nascimento, em fevereiro de 2013, foi realizado para salvar a vida da irmã mais velha, Maria Vitória, que sofria de talassemia major, doença genética que poderia levá-la à morte. A irmã mais nova foi gerada a partir de um embrião selecionado por meio de um tratamento de fertilização in vitro, com o intuito de ser totalmente compatível com a irmã mais velha. Maria Vitória recebeu o transplante de medula óssea a partir de células-tronco e hoje está curada.

No entanto, alguns pesquisadores acreditam que, com a seleção e melhoria da espécie humana, não haverá somente a redução da incidência de enfermidades genéticas graves, mas também serão alcançados níveis desconhecidos, como pessoas dotadas de inteligência sobre-humana. Essa aparente vantagem do avanço genético, na verdade, poderia 
criar medidas desenfreadas de seleção de genes, pela busca da "perfeição" de um padrão ideal, o que acarretaria numa sociedade com seres humanos pré-pensados e aproximados de um estereótipo, de forma semelhante ao ocorrido no nazismo (Buchanan et al., 2002).

A palavra eugenia ${ }^{2}$ é, por isso, comumente associada ao nacional-socialismo, que, de fato, popularizou a expressão. O método implementado pelos médicos do governo era apoiado por uma legislação que, na letra fria, deixava claros seus objetivos e o público-alvo, como, por exemplo, a esterilização de deficientes hereditários e a castração de delinquentes habituais. O principal era impedir a reprodução de pessoas física e biologicamente inaptas, como demonstra o texto básico da legislação eugênica:

"Ley para impedir la transmisión de taras hereditarias" (promulgada el 14 de julio de 1933). Esa ley permite la esterilización en casos de: 1) imbecilidad congénita, 2) esquizofrenia, 2) manía depresiva, 4) epilepsia hereditaria, 5) corea de Huntington, 6) ceguera hereditaria, 7) sordera hereditaria, 8) deformaciones físicas graves hereditarias. El paciente, el médico o el director de la institución en que está confinado aquél pueden recurrir a un tribunal especial de esterilización, que tiene una composición muy semejante y cuya sentencia es ejecutoria. (Neumann, 1943, p. 137)

O fenômeno do holocausto, como se sabe, aniquilou milhões de pessoas com

2 Éimportante destacar que a eugenia perpetrada pelo nazismo é tida como negativa. fins de concretizar um plano de pureza racial, um dos pilares da ideologia estatal do período nazista. Milhares de sujeitos considerados indignos, como esquizofrênicos e deficientes físicos, responsáveis por "impedir" a supremacia racial ariana, idealizada pela perspectiva de uma sociedade perfeita, foram torturados, utilizados como cobaias em experimentos científicos e dizimados. Judeus e ciganos também participaram dos experimentos, enquanto os saudáveis desses grupos recebiam doses de vírus e bactérias, como malária e tifo, para verificar a reação do organismo. Gêmeos e anões eram os preferidos de muitos médicos, sendo especialmente selecionados para experimentos que envolviam a análise de DNA.

Diante de tais considerações, se, de um lado, a eugenia possibilita uma geração de nascidos que poderá crescer livre da ameaça de alguns tipos de enfermidades, de outro, a face negativa do fenômeno demonstra existir o risco de serem criadas novas formas de segregação ao tirar de cada um a própria existência, com qualidades e defeitos característicos do gênero humano. Ao longo da história, observam-se, em vários momentos, indivíduos que, de alguma forma, não se encaixam nos padrões de estereótipo definidos pelo grupo dominante, sendo segregados e perseguidos. O preconceito atravessou séculos, apenas assumindo novos ares, ganhando força no século XIX, com estudos pseudocientíficos sobre a escala de superioridade dos seres humanos, de acordo com seus traços fenotípicos. 


\section{$1.2 \mathrm{~A}$ Intervenção genética ante a dignidade humana}

Os avanços científicos colocam a humanidade diante de um novo panorama evolutivo, ante o acelerado desenvolvimento da indústria farmacêutica ${ }^{3}$ e dos progressos da medicina, principalmente no que tange à manipulação genética. Entretanto, esse fenômeno não pode ser dissociado da raiz ocidental dos direitos, em especial a dignidade da pessoa humana.

Ao selecionar, por intermédio de um controle social dos cruzamentos, determinados traços físicos (os que não possuem alguma deficiência física como a cegueira ou surdez, ou, ainda, com o modelo estético considerado inferior), comportamentais (os mais capazes, fortes e inteligentes), a eugenia, mesmo a positiva, propaga o abuso da discriminação, o que resulta em uma categorização de quem é apto ou não para a reprodução. Habermas chama o resultado disso de "efeito bola de neve", ou seja, com a aceitação prévia de uma eugenia negativa ${ }^{4}$ (desde os abortos seletivos até a terapia de células e substituição da linha germinal), corre-se o risco, pela habitualidade, de cair em uma eugenia positiva, voltada para o aperfeiçoamento, desconsiderando as dimensões morais da pessoa.

Barretto (2013. p. 334) afirma que, segundo o ponto de vista de Habermas, essas

3 Cite-se, a propósito, o surgimento de novos medicamentos como o Solanezumab, anticonvulsivo que pode evitar a evolução da doença de Alzheimer.

4 Para Habermas, a eugenia negativa (aperfeiçoamento) é uma heterodeterminação externa irreversível (atitude do artesão) intervenções (tecnização da natureza humana) atentam contra as condições de formação da identidade do ser afetado, pois provocam uma "alteração de autocompreensão ética da espécie - uma autocompreensão que não pode mais ser harmonizada com aquela autocompreensão normativa, pertencente a pessoas que determinam sua própria vida e agem com responsabilidade".

Assim, a concepção habermasiana demonstra preocupação com a utilização das técnicas genéticas, pois a sua utilização viola os pressupostos essenciais das ações responsáveis surgidas em um contexto de igualdade de condições (Barretto, 2013). Em síntese, ocorre a desnaturalização da espécie humana pelo fenômeno da cientificação, a partir do momento em que a autonomia individual deixa de existir, já que o sujeito não se autolegisla. A humanidade recai nas mãos dos cientistas, através de uma heteronomia a partir do desenvolvimento tecnológico, que se encarrega na produção da vida humana sob padrões preferenciais pragmaticamente selecionados.

Negar o direito à existência dos indivíduos que, em tese, não teriam as "melhores" qualidades não parece ser apenas uma proposta questionável - afinal, os critérios estipulados parecem se vincular com ideologias -, mas também pode ser interpretado como uma tentativa radical de exterminar toda e qualquer forma de diferenças. Como consequência, isso acaba proliferando pessoas incapazes de conviver com o pluralismo biológico e, por conseguinte, social, e, assim, im- 
possibilita-se a evolução do "eu" e do "tu" diversificados.

Todas essas considerações caminham para uma constatação inevitável: a expressão eugenia pode ser considerada paradigmática. Se, por um lado, a humanidade evolui no tratamento das doenças genéticas, por outro, ocorrem indignações quanto à eugenia positiva, em que a heterodeterminação do indivíduo é irreversível (Habermas, 2001), por se tratar de aperfeiçoamento feito por artesão e, por consequência, gerar um ambiente de instrumentalização da espécie humana.

Com a utilização de técnicas genéticas de aperfeiçoamento, ocorre a perda da consciência de autoridade da vida própria, pois o sujeito é submetido às intenções irreversíveis fixadas por agentes exteriores que não ela (heterodeterminação externa); isso gera, por consequência, a impossibilidade do ser de se compreender como autor de sua própria vida (Habermas, 2004).

Analisando os precedentes judiciais brasileiros, é possível encontrar casos de pais que pleiteiam alvará judicial para a interrupção de gravidez, em uma visível tentativa de "escolher" quem pode nascer ou não, a depender dos traços físicos. Em um dos casos, julgado pelo Tribunal de Justiça do Mato Grosso do Sul, um casal entrou com o pedido de interrupção, por ter sido constatado que o feto era portador de hidrocefalia (Tribunal de Justiça do Mato Grosso do Sul [TJ-MS], 2002). Ocorre que, em que pesem as consequências trazidas pela hidrocefalia (problemas de aprendizagem, entre os quais, memória curta e concentração, alterações de personalidade), ela em nada impede a vida extrauterina, razão pela qual foi negada a interrupção da gravidez, sendo garantido ao feto o direito de nascer com vida.

Em outro caso, julgado pelo Tribunal de Justiça do Rio Grande do Sul, o pedido de interrupção de gestação se deu pelo fato de o feto ser portador de artogripose (Tribunal de Justiça do Rio Grande do Sul [TJ-RS], 2013). Trata-se de uma deformidade física, uma doença congênita caracterizada por deformidade e rigidez nas articulações. Apesar das deformidades físicas, normalmente possui desenvolvimento mental normal. Foi negado o pedido, por não se tratar de aborto necessário.

Em ambos os casos, não se estava diante de um perigo considerável à saúde, que acarretasse perigo à vida da gestante, ou da impossibilidade vital após o nascimento. Pelo contrário, o máximo de afetação era em relação ao padrão normal de desenvolvimento, querendo os pais a liberdade de rejeitar o nascimento de seu filho em virtude de imperfeições. Isso acaba remetendo a uma forma de segregação, visto que, em ambos os casos, haveria aptidão para se ter uma vida, tendo em vista a possibilidade de intervenções cirúrgicas capazes de beneficiar o sujeito portador de deficiência.

De forma similar às situações supramencionadas é a interrupção de gravidez que envolve fetos com microcefalia, pois a vida, pela Constituição Federal da República Federativa do Brasil, é um direito fundamental indisponível, o que indicaria 
a interrupção fora dos casos permitidos constitucionalmente, aproximando-se de uma forma de eugenia negativa. Entretanto, no caso do surto de microcefalia registrado nos últimos anos, a responsabilidade do acometimento passa a ser do Estado, devido à omissão da proliferação da doença, tendo em vista a ausência de medidas efetivas para evitar seu avanço. O problema também está na relação da condição financeira dos atingidos com o avanço da epidemia, colocando pessoas em situação vulnerável em uma posição social ainda mais desvantajosa. A questão, portanto, gira em torno da obrigação de levar a gravidez adiante, sabendo das condições inóspitas de muitas famílias e da falta de assistência estatal no combate ao surto de microcefalia.

Em situações normais, ao buscar a interrupção da gestação por conta de deficiências, nega-se a dignidade humana, compreendida como a condição humana como valor único e incondicional que tem a existência de todo ser humano, independentemente de qualquer "qualidade acessória", como o estado de saúde física ou mental (Andorno, 2009). Sabe-se que o aborto de fetos microcéfalos é considerado uma forma de eugenia negativa, entretanto, na atual conjuntura brasileira, é complexo negar o direito de aborto nessa situação.

\section{A EUGENIA NEGATIVA EM JOHN RAWLS}

John Rawls, na estruturação de sua "Uma Teoria da Justiça", parte de uma tradição contratualista em que pessoas livres e racionais se reúnem em uma situação inicial ideal - a posição original — para moldar um acordo social. Nela, todos estariam sob a égide do "véu da ignorância", segundo o qual cada componente estaria impossibilitado de reconhecer todas as circunstâncias pessoais, dos outros e da própria sociedade, de forma que a deliberação partisse somente dos princípios da justiça, fundadores da justiça como equidade (Rawls, 2008).

Após definido o ideal de justo, há a sua materialização em uma constituição e em uma legislatura para a promulgação de normas, desde a concepção inicial acordada. As instituições, posteriormente criadas, têm a função de realizar os fundamentos constitucionais estabelecidos. A posição original, então, é "o status quo inicial apropriado para garantir que acordos fundamentais nele alcançados sejam equitativos" (Rawls, 2008, p. 21). Para tanto, na situação primeva, pressupõe-se que as pessoas não possuam interesses egoísticos, devendo desconhecer da sua própria situação. Na escolha dos princípios, não pode haver quaisquer (des) favorecimentos, necessitando, ainda, de um consenso sobreposto, o qual deve se afastar de situações individuais pela aceitação geral, cuja justificativa pode ser aceita globalmente.

Os dois princípios da justiça como equidade escolhidos na situação inicial são: (1) o da maximização da liberdade igual e (2) o da diferença:

O que sustentarei é que as pessoas presentes na situação inicial escolheriam dois princípios bem diferentes: o primeiro requer igual- 
dade na atribuição dos direitos e dos deveres fundamentais, ao passo que o segundo afirma que as desigualdades de riqueza e autoridade só serão justas se resultarem em vantagens recompensadoras para todos e, em especial, para os membros menos favorecidos da sociedade. (Rawls, 2008, p. 18)

Os princípios, ao serem estabelecidos na posição original, serão, então, a estrutura basilar da formação da sociedade, distribuindo os direitos fundamentais. O autor não apresenta os dois princípios em uma disposição aleatória, mas sim graduada lexicalmente: o primeiro deve ser totalmente satisfeito (de forma irrestrita), ou seja, assegurar as liberdades individuais de todos, para que o princípio da diferença seja aplicado. A relativização do primeiro princípio não ocorre pelo fato de que nenhuma liberdade pode ser violada, justificada por maiores vantagens econômicas e sociais. O único tipo de limitação que pode caber é quando duas liberdades fundamentais entram em choque, já que nenhuma delas é absoluta (Rawls, 2008).

As liberdades fundamentais, é importante ressaltar, são as seguintes: a liberdade política, como o direito ao voto e ao cargo público; a liberdade de expressão e reunião; a liberdade de pensamento; o direito à propriedade privada; a liberdade individual, como proteção contra a opressão psicológica, a agressão e a mutilação que compreendem a integridade da pessoa (Rawls, 2008).

Rawls (2008) demonstra, com isso, que se deve, pois, garantir um status libertário igual, situação na qual um indivíduo não seja mais "livre" do que outro. Todavia, deve-se mencionar que essa situação não é meramente declaratória, ou seja, formal, mas tem um sentido prático, posto que as pessoas possuem desigualdades inerentes entre si na própria substancialidade. Assim, o ser representa a concretização do dever ser, o que permite a vinculação do plano ideal com o real.

No princípio da diferença, ocorre a procura de efetivar a justiça distributiva, em que os que se encontram em posição mais favorecida ou privilegiada só podem ascender sob a hipótese de que isso traga favorecimento a todos, incluindo os menos favorecidos. Em suas palavras, "embora a distribuição de riqueza e renda não precise ser igual, deve ser vantajosa para todos e, ao mesmo tempo, os cargos de autoridade e responsabilidade devem ser acessíveis a todos" (Rawls, 2008, p. 74).

Toda essa configuração moral acaba refletindo no entendimento rawlsiano sobre a eugenia. O autor Rawls acredita que ela é um problema social, uma vez que certas manipulações genéticas, embora possam ser permitidas, não podem atingir os princípios da justiça e devem ser feitas a partir de uma concepção positiva. Assim, para Rawls (2008):

Devemos observar, porém, que em geral não é benéfico para os menos afortunados propor políticas que reduzam os talentos dos outros. Pelo contrário, ao se aceitar o princípio da diferença, os talentos superiores passam a ser considerados bens sociais 
a serem usados para o bem comum. Mas também é do interesse de cada um ter maiores dotes naturais. Isso permite que cada qual possa perseguir seu plano de vida preferido. Na posição original, então, as partes querem garantir para os descendentes a melhor dotação genética (pressupondo-se que a deles próprios esteja determinada). A busca de políticas razoáveis nesse aspecto é algo que as gerações anteriores devem às posteriores, sendo essa uma questão que surge entre as gerações. Assim, com o tempo, a sociedade deve tomar atitudes para ao menos preservar o nível geral das capacidades naturais a fim de impedir a proliferação de defeitos graves. Essas medidas devem ser orientadas por princípios com os quais as partes estariam dispostas a concordar para o bem de seus sucessores. (p. 129)

Segundo a análise da Teoria da Justiça, todas as desvantagens não merecidas, o que inclui traços genéticos menos desejáveis, como deficiências mental e física, não necessitam de uma solução para estabelecer uma situação equitativa. Pelo contrário, a igualdade de oportunidades afirma que é injusto estruturar as instituições sociais de tal forma que o acesso das pessoas aos bens se baseiem nos seus dotes naturais. Nessa mesma linha, a igualdade de oportunidades não requer a ocorrência de intervenção para prevenir todos os casos em que os indivíduos tiverem doenças genéticas.

Para o pensamento seguido pelo autor, as desigualdades naturais, como é o caso do feto cometido pela microcefalia, não se- riam problemáticas, pois "na justiça como equidade, a sociedade é interpretada como um empreendimento cooperativo para o benefício de todos" (Rawls, 2008, p. 102). O princípio de oportunidades equitativas deve garantir que o sistema de cooperação seja um sistema de justiça procedimental pura, que não leva em consideração as circunstâncias nem as posições relativas mutáveis das pessoas. A distribuição dos itens produzidos será conduzida através de um sistema público de normas, que definirá as exigências e dependerá das reivindicações dos indivíduos.

O princípio de diferença tenta estabelecer fundamentos objetivos para as comparações interpessoais de duas maneiras. Em primeiro lugar, se pudermos identificar o indivíduo representativo menos favorecido, daí em diante só há a necessidade de juízos ordinais de bem-estar. Sabemos a partir de qual posição se deve julgar o sistema social. Não importa o quanto esse indivíduo representativo é menos desfavorecido em relação aos outros. As outras dificuldades de aferição cardinal não se apresentam, pois não há necessidade de quaisquer comparações interpessoais (Rawls, 2008, pp.109-110).

Sob o ponto de vista de Rawls, cidadãos portadores de deficiência serão tão sujeitos quanto outros considerados "normais", garantidamente pelo sistema cooperativo, através do princípio da diferença, em que os detentores de posições mais privilegiadas deverão colaborar com os menos favorecidos, a fim de estabelecer uma equidade social. 
O autor destaca o princípio do paternalismo, utilizado no caso de crianças, deficientes mentais, ou qualquer pessoa que não tenha condições de promover racionalmente seus interesses. Os seus termos, então reconhecidos pelas partes na posição original, possuem o intuito de proteger os contratantes contra fraquezas e enfermidades de sua razão e vontade na sociedade. Diante disso, terceiros recebem o direito, ou até mesmo a exigência, de agir em nome alheio para fazer o que nós mesmos faríamos em uma situação racional.

As decisões devem ser orientadas pela manifestação dos interesses individuais, desde que "racionais". Quando se age em nome de algum desconhecido, da mesma forma, é necessário agir por ele como agiria de forma própria, tentando consolidar o "melhor" (Rawls, 2008). Esses princípios são considerados proteção da própria irracionalidade do ser humano e não devem ser interpretados como autorizações a agressões contra esse indivíduo.

Duas outras estipulações se fazem necessárias: a intervenção paternalista deve justificar-se pela evidente deficiência ou ausência da razão e da vontade, e deve orientar-se pelos princípios de justiça e pelo que se sabe dos objetivos e das preferências mais permanentes do indivíduo; ou pela teoria dos bens primários. Essas limitações impostas à aplicação e orientação de medidas paternalistas derivam das suposições da posição original. As partes querem garantir a própria integridade pessoal, bem como suas crenças e seus objetivos últimos, quaisquer que sejam (Rawls, 2008, p. 310).

O autor expressa, através do princípio paternalista, que mesmo o indivíduo sem racionalidade deve ser tutelado por aquele dotado de racionalidade plena. Nesse sentido, pode-se observar que Rawls é claro ao afirmar que não serão permitidas agressões à sua integridade física; assim, a interrupção da gestação de fetos microcéfalos seria algo inadmissível para a teoria do autor.

Ao enumerar um elenco (não taxativo) de liberdades básicas, a liberdade individual, vista como valor "supremo", norteia o alcance do bem-estar da sociedade; portanto, a intervenção genética, sob forma de eugenia negativa, como podem ser considerados alguns casos de interrupção da gravidez por conta de feto microcéfalo, não poderia, em um primeiro momento, ser aceita, por ferir a integridade da pessoa. Nessa situação, trata-se da liberdade individual do feto que será impedido de nascer. Entretanto, há uma pergunta: e a escolha da mulher não estaria resguardada sob os mesmos fundamentos?

A resposta deve perpassar os elementos reais constitutivos da sociedade. No caso do Brasil, a Constituição Federal, dotada de força normativa, tem o direito à vida como fundamental, e o Código Civil tutela os direitos do nascituro desde a sua concepção $\left(\operatorname{art.} 2^{\circ}\right)$. A interrupção da gravidez estaria ferindo, na própria tradição conceitual de vida, os princípios de justiça e as normas estabelecidas no pacto inicial, embora nada trave eventuais 
mudanças de cunho constitucional em sentido diverso, desde que possibilite a participação de todos no procedimento deliberativo de modo a consubstanciar o consenso sobreposto, afastado de eventuais doutrinas abrangentes não razoáveis ou por escusas de cunho pessoal das maiorias transitórias, como pode ser o caso da religião.

Ao longo de seus estudos, portanto, Rawls deixa "pistas" a respeito do que considera inadmissível para a sociedade bem ordenada, e percebe-se que todos os argumentos unidos se tornam uma voz uníssona, a fim de comprovar que a Teoria da Justiça do autor é incompatível com a instrumentalidade utilitarista da eugenia negativa, ou qualquer outro tipo de situação que viole a dignidade humana. Em contrapartida, busca resguardar o máximo possível de atuação da liberdade da mulher e de todos os demais cidadãos.

\section{CONCLUSÕES}

O trabalho procurou inicialmente fazer um panorama geral do significado de eugenia, desde seu surgimento, através de Francis Galton, até a contemporaneidade. Verificou-se que o termo carrega uma sombra por conta do ápice de sua popularidade ter se dado na ocasião dos estudos nazistas, embora seja possível visualizar situações em que a sua utilização ocasione, de alguma forma, melhorias significativas na saúde humana.

Após a exposição das categorias que envolvem a eugenia e a análise de casos, chegou-se à conclusão de que a interrup- ção da gestação de fetos anencéfalos se enquadra, em certas situações, na eugenia negativa, por somente visar à maximização do bem-estar social, ainda que em detrimento de alguns poucos indivíduos, podendo citar, como atitude análoga, o aborto seletivo.

Como pano de fundo da problemática escolhida, a Teoria da Justiça de John Rawls foi exposta para dar os fundamentos necessários para a discussão sobre o posicionamento social acerca de certos tópicos e, como visto, a sua formação se inicia a partir de um contrato no qual os membros, vestidos com o "véu da ignorância" para se restringir apenas aos princípios de justiça — da maximização da liberdade individual e o da diferença - , possam estabelecer os pilares constitucionais e, por conseguinte, assegurar a não ocorrência da eugenia negativa, vista aqui como uma forma de instrumentalização desarrazoada. Caso se considere apenas o bem-estar coletivo como, por exemplo, o estabelecimento de "padrões superiores", a interrupção da gravidez por conta da microcefalia estaria vedada, de início, sobretudo pelas escolhas feitas, no Brasil, pelos contratantes iniciais.

Todavia, nada veda a liberdade da mulher em escolher sobre o seu próprio corpo, desde que as suas escolhas se adaptem à ordem normativa, o que, por conseguinte, significa estabelecer uma simetria com argumentos capazes de se fazer racionais dentro da égide do consenso sobreposto. Para complementar, portanto, é relevante notar o pensamento de Habermas no sentido de afirmar que não apoia técnicas de 
aperfeiçoamento humano, isto é, é contra todos os tipos de eugenia.

Assim, avanços genéticos são importantes, contanto que, além de favorecerem a sociedade, entrem em consonância com os princípios da justiça e evitem qualquer medida invasiva de doutrinas abrangentes não razoáveis no locus técnico-científico e da razão pública, o que, invariavelmente, pode - e é bem provável que vá — levar a uma restrição da liberdade ao invés de sua expansão.

\section{REFERÊNCIAS}

Andorno, R. (2009). Liberdade e Dignidade da pessoa: dois paradigmas opostos ou complementares na bioética? Em J. M. Costa e L. L. Möller (eds.), Bioética e Responsabilidade (pp. 73-93). Rio de Janeiro, Brasil: Forense.

Barretto, V. P. (2013). O fetiche dos Direitos Humanos e outros Temas. Porto Alegre, Brasil: Livraria do Advogado.

Buchanan, A., Brock, D., Daniels, N. e Wikler, D. (2002). Genética y justicia. Madri, Espanha: Cambridge University Press.

Cowan, R. S. (1972). Francis Galton's statistical ideas: the influence of eugenics. Isis, 63(4), 509-528.

Del Cont, V. (2008). Francis Galton: eugenia e hereditariedade. Scientiae Studia, 6(2), 201-218.

Domingues, O. (1942). Eugenia. São Paulo, Brasil: Companhia Editora Nacional.

Feldhaus, C. (2005). O futuro da natureza humana de Jürgen Habermas: um comentário. Ethic@, 4(3), 309-319.
Galton, F. (1988). Herencia y eugenesia. Madri, Espanha: Alianza Editorial.

Habermas, J. (2001). A Constelação pós-nacional: Ensaios políticos. São Paulo, Brasil: Littera Mundi.

Habermas, J. (2004). O futuro da natureza humana: a caminho de uma eugenia liberal? São Paulo, Brasil: Martins Fontes.

Ministério da Saúde do Brasil. (2015). Protocolo de vigilância e resposta à ocorrência de microcefalia relacionada à infecção pelo vírus Zika. Recuperado de http://portalarquivos2.saude.gov.br/ images/pdf/2015/dezembro/09 Microcefalia- -Protocolo-de- vigil- -ncia-e-resposta- -vers- -0- 1 - - -09dez2015-8h.pdf

Mota, A. (2013). Quem Tem Medo da Eugenia?: Permanências Discursivas de uma Prática Inacabada. Em Monteiro Y. e Carneiro M. (eds.), As doenças e os medos sociais (pp. 219-250). São Paulo: Editora da Universidade Federal de São Paulo.

Neumann, F. (1943). Behemoth: pensamiento y acción en el Nacional Socialismo. Cidade do México, México: Fondo de Cultura Económica.

Rawls, J. (2008). Uma Teoria da Justiça. São Paulo, Brasil: Martins Fontes.

Tribunal de Justiça do Mato Grosso do Sul, Quarta Turma Cível. (25 de fevereiro de 2002) Sentença AC: 466 MS 2002.000466-0 [MP. João Maria Lós]

Tribunal de Justiça do Rio Grande do Sul, Segunda Câmara Criminal. (24 de outubro de 2013) Sentença ACR: 70056632276 RS IMP. Marco Aurélio de Oliveira Canosa] 